\title{
Relationship Of Job Satisfaction And Organizational Commitment To Turnover Intention In PT. Mega Kapuas Multiniaga Employees In Jakarta
}

\author{
Michael Candra Jaya and I Putu Artaya \\ Program Studi Manajemen, Fakultas Ekonomi Dan Bisnis \\ Universitas Narotama Surabaya \\ Email Author: putu.artaya@ narotama.ac.id
}

\begin{abstract}
This study aims to determine the relationship between job satisfaction and organizational commitment to the turnover intention of employees of PT. Megakapuas Multiniaga in Jakarta. This study uses a quantitative approach. The population in this study were employees of PT. Megakapuas Multiniaga in Jakarta. The sample used is 100 respondents using a questionnaire that is distributed directly to the respondents. Meanwhile, the analysis technique used is to use the correlation method in two ways, namely the calculation of the formula and SPSS 16.0. The results of the questionnaire data calculation state that the independent variables, namely job satisfaction (X1) and organizational commitment (X2), have a positive and insignificant relationship to turnover intention. The test of the men instrument in this study used the validity test, reliability test, correlation test using the calculation formula, and using the Spearman rank correlation test. The results showed that there was an influence between job satisfaction and organizational commitment on turnover intention. Based on the results of testing the variable job satisfaction to turnover intention, the value of $\mathrm{r}$ count is 0.058 with a significance of $0.578>0.05$ and organizational commitment to turnover intention, it is known that the value of r-count is 0.049 with a significance of $0.487>0.05$. In this study, there are 2 hypotheses. The first hypothesis states that job satisfaction has a positive and insignificant relationship with turnover intention and the second hypothesis states that organizational commitment has a positive and insignificant relationship with turnover intention.
\end{abstract}

\section{Keyword:}

Job Satisfaction, Organizational Commitment, Turnover Intention.

\section{Pendahuluan}

Beberapa perusahaan kurang mengganggap penting akan arti komitmen dan kepuasan kerja. Karena pasar tenaga kerja yang ada memungkinkan bagi mereka untuk mengganti keberadaan karyawan yang merasa tidak sesuai dengan kepentingan mereka dengan karyawan baru. Padahal dengan meningkatnya komitmen karyawan, perusahaan akan mendapatkan banyak sekali keuntungan yang terkait hal tersebut. Seperti produktivitas dan efektifitas waktu kerja, jika karyawan memiliki komitmen yang tinggi, maka perusahaan akan mendapatkan dampak positif antara lain, peningkatan produktivitas, kualitas kerja, serta menurunnya tingkat keterlambatan kerja (Andini, 2006). Sehubungan dengan munculnya turnover intention, karyawan yang memiliki kepuasan kerja akan lebih produktif, memberikan kontribusi terhadap sasaran dan tujuan organisasi, dan pada umumnya memiliki keinginan yang rendah untuk keluar dari perusahaan. Kepuasan pada dasarnya merupakan suatu hal yang bersifat pribadi, karena kebutuhan dan keinginan akan kepuasan dari setiap individu sangat berbeda antara satu dengan yang lainnya (Andini, 2006).

\section{Tinjauan Pustaka}

\subsection{Kepuasan Kerja}

Menurut (Syaiin, 2006), Kepuasan Kerja merupakan sikap umum yang merupakan hasil dari beberapa sikap khusus terhadap faktor- faktor pekerjaan, penyesuian diri dan hubungan sosial individu di luar kerja. Kepuasan Kerja pada dasarnya adalah "security feeling" (rasa aman) dan dibedakan dari dua segi, yaitu:

1. Segi sosial ekonomi (gaji dan jaminan sosial).

2. Segi sosial psikologi :

1) Kesempatan untuk maju

2) Kesempatan mendapatkan penghargaan 
3) Berhubungan dengan masalah pengawasan

4) Berhubungan dengan pergaulan antara karyawan dengan karyawan dan antara keryawan dengan atasannya (Hadi, 2001 dalam Syaiin, 2006).

\title{
2.2. Komitmen Organisasional
}

Komitmen Organisasional didefinisikan sebagai suatu konstruk psikologis yang merupakan karakteristik hubungan antara anggota organisasi dengan organisasinya dan memiliki implikasi terhadap keputusan individu untuk melanjutkan keanggotaannya dalam berorganisasi (Carolina, 2012).

\subsection{Turnover Intention}

Menurut (Carolina, 2012), Turnover Intentions ditandai oleh berbagai hal yang menyangkut perilaku karyawan, yang meliputi: absensi yang meningkat, mulai malas kerja, naiknya keberanian untuk melanggar tata tertib kerja, keberanian untuk menentang atau protes kepada atasan, maupun keseriusan untuk menyelesaikan semua tanggung jawab karyawan yang sangat berbeda dari biasanya. Indikasi-indikasi tersebut bisa digunakan sebagai acuan untuk memprediksi Turnover Intentions karyawan dalam sebuah perusahaan.

\section{Metode Penelitian}

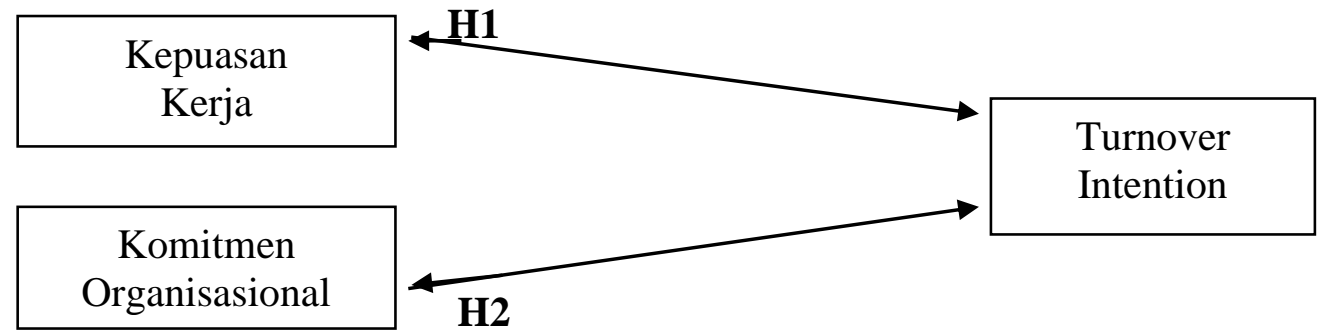

\author{
Gambar 1. Model Penelitian \\ Sumber: Yaqin (2013); Handaru dan Muna (2012)
}

\subsection{Jenis dan Teknik Pengambilan Data}

Dapat disimpulkan dalam penelitian ini menggunakan data primer dan data kuantitatif. Data primer merupakan data yang diperoleh dari pengisian kuesioner responden secara keseluruhan, sedangkan data kuantitatif merupakan data penelitian menggunakan angka-angka melalui kuesioner dan menjadi olahan data statistik aplikasi SPSS 18.0.

\subsection{Teknik Pengambilan Data}

Alat yang digunakan dalam penelitian berupa kuesioner yang dibagikan secara langsung kepada responden yang merupakan karyawan PT. Megakapuas Multiniaga di Jakarta. Metode pengumpulan data dalam penelitian ini adalah metode survey.

\subsection{Populasi dan Sampel}

\subsubsection{Populasi}

Populasi adalah objek dan benda-benda yang diamati oleh peneliti, popoulasi juga bukan sekedar jumlah yang ada pada objek/subjek yang diamati, melainkan keseluruhan karakteristik/sifat yang dimiliki oleh subjek/subjek untuk dipelajari kemudian diambil kesimpulan (Sugiyono, 2014:80). Populasi penelitian adalah PT. Megakapuas Multiniaga di Jakarta dengan keseluruhan 110 karyawan.

\subsubsection{Sampel}

Sampel yang diambil berdasarkan sampel yang diambil dari populasi pada karyawan PT. Megakapuas Multiniaga di Jakarta ini sampel berjumlah 100 responden. Hal tersebut dikarenakan karyawan karyawan keseluruhan berjumlah 100, diantaranya 10 di bagian manajerial (direktur dan manajer), sedangkan sisanya 100 karyawan pada bagian non manajerial di PT. Megakapuas Multiniaga di Jakarta karena Jakarta merupakan perusahaan pusat yang memiliki karyawan terbanyak diantara cabang Surabaya dan Semarang. 


\subsection{Uji Validitas}

Adapun hasil dari pengujian validitas masing-masing variabel dapat dilihat pada tabel-tabel dibawah ini:

Tabel 1. Uji Validitas

\begin{tabular}{cccc}
\hline Indikator & Pearson Correlation & Sig. (2-tailed) & Keterangan \\
\hline KK1 & 0.775 & 0,00 & Valid \\
KK2 & 0.738 & 0,00 & Valid \\
KK3 & 0.793 & 0,00 & Valid \\
KK4 & 0.728 & 0,00 & Valid \\
KK5 & 0.733 & 0,00 & Valid \\
KK6 & 0.716 & 0,00 & Valid \\
KK7 & 0.685 & 0,00 & Valid \\
KK8 & 0.719 & 0,00 & Valid \\
KO1 & 0.690 & 0,00 & Valid \\
KO2 & 0.702 & 0,00 & Valid \\
KO3 & 0.671 & 0,00 & Valid \\
KO4 & 0.769 & 0,00 & Valid \\
KO5 & 0.817 & 0,00 & Valid \\
KO6 & 0.720 & 0,00 & Valid \\
KO7 & 0.687 & 0,00 & Valid \\
KO8 & 0.790 & 0,00 & Valid \\
KO9 & 0.638 & 0,00 & Valid \\
KO10 & 0.666 & 0,00 & Valid \\
KO11 & 0.775 & 0,00 & Valid \\
TI1 & 0.863 & 0,00 & Valid \\
TI2 & 0.859 & 0,00 & Valid \\
TI3 & 0.836 & 0,00 & Valid \\
\hline
\end{tabular}

Berdasarkan Tabel 1, diketahui nilai probabilitas $<0,05$ berarti angka probabilitas tersebut signifikan sehingga dapat disimpulkan bahwa masing-masing item pertanyaan pada variabel kepuasan kerja, komitmen organisasi dan turnover intention dinyatakan valid.

\subsection{Uji Reliabilitas}

Uji reliabilitas adalah alat untuk mengukur suatu kuisioner yang mempunyai indikator dari variabel atau konstruk. Suatu kuisioner dinyatakan reliabel atau handal jika jawaban seseorang terhadap pernyataan adalah konsisten atau stabil dari waktu ke waktu (Ghozali, 2006:41). SPSS memberikan fasilitas untuk mengukur reliabilitas dengan uji statistic Croanboach Alpha. Suatu konstruk atau variabel dikatakan reliabel jika memberikan nilai Croanboach Alpha > 0,6 (Ghozali, 2006:42).

Tabel 2. Uji Reliabilitas

\begin{tabular}{clcc}
\hline No & \multicolumn{1}{c}{ Variabel } & $\begin{array}{c}\text { Cronbach } \\
\text { Alpha }\end{array}$ & Keterangan \\
\hline 1 & Kepuasan Kerja & 0.882 & Reliabel \\
2 & Komitmen Organisasional & 0,931 & Reliabel \\
3 & Turnover Intention & 0,932 & Reliabel \\
\hline
\end{tabular}
diatas 0,6 .

Berdasarkan Tabel 2. diketahui bahwa variabel penelitian sudah reliabel, karena nilai Cronbach Alpha $(\alpha)$

\subsection{Analisis Korelasi}

Analisis korelasi ini untuk memprediksi suatu variabel berdasarkan beberapa variabel lainnya. Serta untuk menjelaskan pengaruh variabel bebas terhadap variabel terikat. 
Tabel 3. Interpretasi Nilai $r$

\begin{tabular}{cc}
\hline Interval Koefisien & Tingkat Hubungan \\
\hline $0,80-1,000$ & Sangat Kuat \\
$0,60-0,799$ & Kuat \\
$0,40-0,599$ & Cukup Kuat \\
$0,20-0,399$ & Rendah \\
$0,00-0,199$ & Sangat Rendah \\
\hline
\end{tabular}

Sumber: Sugiyono (2000:149)

Berdasarkan Tabel 3. sebagai acuan pada nilai r, maka interpretasi yang dapat dijelaskan pada Tabel 4.12 dan Tabel 4.13 adalah sebagai berikut :

Tabel 4. Analisis Nilai r Korelasi

\begin{tabular}{|c|c|c|c|c|c|c|c|c|}
\hline Keterangan & X1 & $\mathrm{X} 2$ & $Y$ & $X 1^{2}$ & $X 2^{2}$ & $Y^{2}$ & X1.Y & X2.Y \\
\hline$\sum$ & 329.75 & 341.09 & 337.33 & 1154.09 & 1223.39 & 1229.11 & 1181.17 & 1210.24 \\
\hline Mean & 3.2975 & 3.4109 & 3.3733 & 11.5409 & 12.2339 & 12.2911 & 11.8117 & 12.1024 \\
\hline
\end{tabular}

Berdasarkan tabel 3. dapat disimpulkan dalam rumus korelasi secara manual, sebagai berikut:

$$
\begin{aligned}
& \mathrm{rX1}=\frac{\mathrm{n} \sum \mathrm{X} 1 \mathrm{Y}-\left(\sum \mathrm{X} 1\right)\left(\sum \mathrm{Y}\right)}{\sqrt{ }\left\{\mathrm{n} \sum \mathrm{X} 12-\left(\sum \mathrm{X} 1\right) 2\right\} \sqrt{ }\left\{\mathrm{n} \sum \mathrm{Y} 2-\left(\sum \mathrm{Y}\right) 2\right\}} \\
& \mathrm{rX1}=\frac{100.1181,17-(329,75) \cdot(337,33)}{\quad \sqrt{ }\{100.1154,09-1154,09\} \sqrt{ }\{100.1229,11-1229,11)}
\end{aligned}
$$

$\mathrm{rX} 1=0,058$

Berdasarkan perhitungan rumus di atas ditemukan nilai $R$ adalah sebesar 0,058. Hal ini dapat diartikan bahwa kontribusi hubungan kepuasan kerja (X1) terhadap Turnover Intention (Y) dapat dikategorikan pada tingkat "sangat rendah/lemah".

$$
\begin{aligned}
& \mathrm{n} \sum \mathrm{X} 2 \mathrm{Y}-\left(\sum \mathrm{X} 2\right)\left(\sum \mathrm{Y}\right) \\
& \mathrm{rX} 2=\frac{}{\sqrt{ }\left\{\mathrm{n} \sum \mathrm{X} 22-\left(\sum \mathrm{X} 2\right) 2\right\} \sqrt{ }\left\{\mathrm{n} \sum \mathrm{Y} 2-\left(\sum \mathrm{Y}\right) 2\right\}} \\
& r X 2=\frac{100 \cdot 341,09-(341,09) \cdot(337,33)}{} \\
& \sqrt{ }\{100.1223,39-1223,39\} \sqrt{ }\{100.1229,11-1229,11)
\end{aligned}
$$

rX2 $=0,049$

Berdasarkan perhitungan rumus di atas ditemukan nilai $\mathrm{R}$ adalah sebesar 0,049. Hal ini dapat diartikan bahwa kontribusi hubungan komitmen organisasional (X2) terhadap Turnover Intention (Y) dapat dikategorikan pada tingkat "sangat rendah/lemah".

\section{Hasil dan Pembahasan}

\subsection{Hasil Uji Korelasi Rank Spearman}

Tujuan utama dari penelitian ini adalah untuk mengukur dan menganalisis kekuatan hubungan antara variabel Kepuasan Kerja (X1), Komitmen Organisasional (X2). Karena data yang digunakan adalah ordinal, maka proses pengolahan data menggunakan analisa korelasi Rank Spearman. Rank Spearman tidak mengikuti asumsi normalitas dan linieritas seperti pada Korelasi Product Moment tidak pula menggunakan data interval sehingga hasil uji 
Spearman ini dapat langsung diinterpretasikan maknanya menggunakan bantuan tabel interpretasi nilai r. Adapun hasil analisis korelasi Rank Spearman adalah sebagai berikut :

Tabel 5. Hasil Uji Korelasi Rank Spearman

\begin{tabular}{|c|c|c|c|c|c|}
\hline \multicolumn{6}{|c|}{ Correlations } \\
\hline & & & KK & $\mathrm{KO}$ & TI \\
\hline \multirow[t]{9}{*}{ Spearman's rho } & KK & Correlation Coefficient & 1.000 & $.231^{* *}$ & $.058^{* *}$ \\
\hline & & Sig. (2-tailed) & . & .000 & .578 \\
\hline & & $\mathrm{N}$ & 100 & 100 & 100 \\
\hline & $\mathrm{KO}$ & Correlation Coefficient & $.236^{* *}$ & 1.000 & $.049^{* *}$ \\
\hline & & Sig. (2-tailed) & .000 & . & .487 \\
\hline & & $\mathrm{N}$ & 100 & 100 & 100 \\
\hline & $\mathrm{TI}$ & Correlation Coefficient & $.058^{* *}$ & $.049^{* *}$ & 1.000 \\
\hline & & Sig. (2-tailed) & .578 & .487 & \\
\hline & & $\mathrm{N}$ & 100 & 100 & 100 \\
\hline
\end{tabular}

**. Correlation is significant at the 0.01 level (2-tailed).

Berdasarkan Tabel 5 , maka interpretasi yang dapat disimpulkan adalah sebagai berikut :

1. Berdasarkan hasil analisis Rank Spearman diatas diketahui nilai rhitung 0,058 dengan signifikansi 0,578 > 0,05. Hal ini berarti terdapat korelasi yang positif dan tidak signifikan antara variabel Kepuasan Kerja (X1) dengan Turnover Intention (Y).

2. Berdasarkan hasil analisis Rank Spearman diatas diketahui nilai rhitung 0,049 dengan signifikansi 0,487 >0,05. Hal ini berarti terdapat korelasi yang positif dan tidak signifikan antara variabel Komitmen Organisasional (X2) dengan Turnover Intention (Y).

\subsection{Pembahasan}

Berdasarkan hasil penelitian hubungan kepuasan kerja sangat kecil/lemah sebesar 0,058 terhadap turnover intention dan hasil uji hipotesis menyatakan kepuasan kerja tidak signifikan terhadap turnover intention. Hal ini membuktikan bahwa karyawan merasakan kepuasan kerja namun tidak menyebabkan turnover intention.

Temuan ini mendukung penelitian dari Yaqin (2013) yang menyatakan bahwa kepuasan kerja tidak berpengaruh terhadap turnover intention. Namun penelitian ini tidak mendukung penelitian Handaru dan Muna (2012) karena penelitian tersebut menyatakan kepuasan gaji dan komitmen organisasi di PT JAMSOSTEK cukup rendah karena adanya peningkatan turnover karyawan setiap tahunnya. Sebagian karyawan menyatakan gaji yang diterima dari perusahaan tidak sesuai dengan pekerjaan yang dilakukan dan menyatakan gaji tidak memotivasi karyawan untuk bekerja lebih baik lagi, ini memberikan indikasi bahwa adanya ketidakpuasan karyawan atas gaji dan kurangnya komitmen karyawan terhadap perusahaan ini.

Berdasarkan hasil penelitian hubungan komitmen organisasional sangat kecil/lemah sebesar 0,049 terhadap turnover intention dan hasil uji hipotesis menyatakan komitmen organisasional tidak signifikan terhadap turnover intention.. Hal ini berarti bahwa karyawan benar-benar berkomitmen pada pekerjaan dan perusahaan sehingga tidak menyebabkan atau tidak terjadi turnover intention. Temuan ini mendukung penelitian dari Yaqin (2013) yang menyatakan bahwa komitmen organisasional berpengaruh negatif terhadap turnover intention karyawan KJPP Toha, Okky, Heru \& Rekan cabang Surabaya. Hasil ini disebabkan karena indikator komitmen organisasi seperti komitmen afektif, komitmen normatif, dan komitmen berkelanjutan (continuance) memiliki tingkatan yang rendah. Komitmen karyawan KJPP Toha, Okky, Heru \& Rekan cabang Surabaya dirasakan rendah, hal ini disebabkan banyaknya tawaran yang lebih menguntungkan dari perusahaan luar sehingga menyebabkan tingkat turnover intention karyawan KJPP Toha, Okky, Heru \& Rekan cabang Surabaya tinggi.

\section{Penutup}

\subsection{Kesimpulan} berikut:

Berdasarkan hasil penelitian yang telah dijelaskan pada bab sebelumnya, dapat ditarik kesimpulan sebagai 
1. Variabel kepuasan kerja memiliki korelasi positif dan tidak signifikan terhadap terjadinya turnover intention di PT. Megakapuas Multiniaga di Jakarta. Dari hasil ini menunjukkan karyawan yang merasa memiliki kepuasan kerja selama di perusahaan, cenderung karyawan tidak memilik niat pada turnover intention karena merasa puas selama karyawan bekerja sehingga tidak berniat untuk keluar dari perusahaan atau mencari alternatif pekerjaan lain.

2. Variabel komitmen organisasional memiliki korelasi positif dan tidak signifikan terhadap terjadinya turnover intention di PT. Megakapuas Multiniaga di Jakarta. Dari hasil ini menunjukkan karyawan memiliki komitmen pada pekerjaan dan perusahaan selama bekerja, sehingga cenderung tidak memiliki niat untuk keluar dari perusahaan atau mencari alternatif pekerjaan lain.

\section{2. Saran}

1. Saran Akademik

Penelitian ini nantinya dapat digunakan sebagai referensi bagi penelitian selanjutnya dalam melakukan penelitian yang sejenis atau sama bahkan dapat dijadikan penelitian lebih lanjut khusus berkaitan konsep atau teori yang mendukung pengetahuan manajemen sumber daya manusia, yaitu mengenai kepuasan kerja dan komitmen organisasional. Selain itu juga, peneliti hendaknya meneliti organizational citizenship behavior dengan menggabungkan penelitian ini dengan penelitian lain yang telah dilakukan, sehingga dengan adanya komitmen karyawan atau loyalitas karyawan dapat mengukur kinerja karyawan dan perusahaan dalam jangka panjangnya.

\section{Saran Praktis}

Berdasarkan hasil penelitian dan pembahasan, saran yang diberikan oleh peneliti sebagai berikut:

a. PT. Megakapuas Multiniaga di Jakarta, pada pernyataan kepuasan kerja mengenai "Saya merasa cukup nyaman dengan kondisi kerja di perusahaan ini" hendaknya meningkatkan kenyamanan tempat kerja karyawan sehingga karyawan merasa selama bekerja benar-benar diperhatikan.

b. PT. Megakapuas Multiniaga di Jakarta, berdasarkan pernyataan karyawan yang rendah mengenai "saya walaupun ingin namun saya sangat berat untuk keluar di perusahaan ini". Hal tersebut perlu diperhatikan dan dibenahi dengan melakukan pendekatan agar komitmen karyawan dapat terwujud dengan baik yaitu dengan memberikan perhatian atas kinerja, memberikan motivasi pada saat bekerja, melakukan pengawasan karyawan yang berkinerja rendah setiap bulannya dan secara langsung berkomunikasi dengan karyawan tersebut untuk mencari tahu penyebab dan alasan karyawan berkinerja rendah pada bulan tersebut.

\section{Daftar Pustaka}

Andini, Rita. (2006). Analisis Pengaruh Kepuasan Gaji, Kepuasan Kerja, Komitmen Organisasional terhadap Turnover Intention. Tesis. Universitas Diponegoro, Semarang.

Arianto, Agus Toly. (2001). Analisis Faktor-faktor yang Mempengaruhi Turnover Intention pada Staff Kantor Akuntan Publik. Jurnal Akutansi dan Keuanagan.

Bagus, Denny. 2009. Teori-teori tentang Kepuasan Kerja dan Dampak Kepuasan dan Ketidakpuasan Kerja.

http://jurnal-sdm.blogspot.com/2009/04/teori-teori-tentang-kepuasan-kerja-dan.html

Christiana dan Sunjoyo. (2010). Pengaruh Kepuasan Kerja terhadap Komitmen Organisasional yang dimediasi oleh Identifikasi Organisasional. Jurusan Manajemen Fakultas Ekonomi Universitas Kristen Maranatha, Bandung.

Carolina. (2012). Pengaruh Iklim Etika terhadap Komitmen Organisasi dan Turnover Intention. Skripsi . Universitas Indonesia.

Chao, Kang-Lin. 2010. Relationship among Organizational Commitment, Job Characteristics, Job Satisfaction, and Turnover Intention within Kindergartens:An Empirical Study in Malaysia.

國立臺南大「教育研究學報」第44卷第1期（民國99.4:179-204.

Djaali, 2008. Skala likert. Jakarta: PustakaUtama

Djastuti, Indi. 2011 Pengaruh Karakteristik Pekerjaan terhadap Komitmen Organisasi Karyawan Tingkat Manegerial Perusahaan Jasa Konstruksi di Jawa Tengah. Jurnal Bisnis dan Akutansi. Universitas Diponegoro.

Ghozali. Imam, 2007, Aplikasi Analisis Multivariate Dengan Program SPSS, Cetakan IV: Badan Penerbit Universitas Diponegoro Semarang, ISBN: 979.704.300.2.

Handara, Agung.W., Muna Nailul. 2012. Pengaruh Kepuasan Gaji Dan Komtmen Organisasi Terhadap Intensi Turnover Pada Divisi PT. JAMSOSTEK. Jurnal Riset Sains Indonesia (JRMSI). Vol. 3. No.1.

Kuncoro. Mudrajad, 2013, Metode Riset Untuk Bisnis Dan Ekonomi. Penerbit:Erlangga.

Labatmediene, Lina. 2007. Individual correlates of organizational commitment and intention to leave the organization. Baltic Journal of Management. Vol. 2 No. 2. pp: 1-35. 
Ridlo, Muhammad. 2012. Faktor-Faktor yang Memepngaruhi Tiurnover Intention Pada Karyawan Perusahaan di Jakarta. Jurnal Ekonomi Manajemen : Hal 136-146.

Sugiyono. (2000). Statistik Untuk Penelitian. Bandung: CV. Alfabeta.

Sugiyono. 2014. Metode Penelitian Kuantitatif, Kualitatif, dan Kombinasi (Mixed Methods). Bandung : Alfabeta.

Susilo. Tri., Analisis Pengaruh Faktor Lingkungan Fisik Dan Non Fisik Terhadap Stress Kerja Pada Pt. Indo Bali Di Kecamatan Negara, Kabupaten Jimbaran, Bali, Jurnal Manajemen, Hal: 1-9.

Syaiin, Subakti. 2006. Pengaruh Kepuasan Kerja Terhadap Kinerja Pegawai Klinik Spesialis Bestari. Tesis. Program Pasca Sarjana Universitas Sumatera Utara. Medan.pp: 1-45.

Toly, Agus Arianto. 2011. Analisis Faktor yang Mempengaruhi Turnover IntentionPada Staff Kantor Akuntan Publik. Jurnal Akuntansi Dan Keuangan: Hal 102-125.

Witasari, Lia. 2009. Analisis Pengaruh Kepuasan Kerja Dan Komitmen Organisasional Terhadap Turnover Intentions (Studi Empiris Pada Novotel Semarang). Tesis. Program Studi Magister Manajemen Program Pasca Sarjana Universitas Diponegoro Semarang.

Yaqin, Muhammad Ainul. 2013. Pengaruh Kepuasan Kerja Dan Komitmen Organisasi Terhadap Turnover Intention Karyawan KJPP, TOHA, OKKY, HERU dan Rekan Cabang Surabaya. Jurnal Ilmu Manajemen. Vol. 1 No.2. 